\title{
THE PROBLEM OF THE CRITERION, KNOWING THAT ONE KNOWS AND INFINITISM
}

Tito Alencar Flores*

SÍNTESE - O problema do critério é um dos mais importantes da epistemologia. A resposta que se dá a ele definirá um aspecto fundamental das teorias do conhecimento. Neste ensaio, o problema do critério é apresentado e algumas das conseqüências geradas pela aceitação de exigências metaepistemicas são analisadas. Em especial, essas conseqüências são avaliadas em relação ao infinitismo - a teoria epistemológica segundo a qual as razões que sustentam nossas crenças devem ser infinitas em número e não-repetidas Ao final, sustenta-se que cláusulas que exigem que a metajustificação seja necessária para o conhecimento não apenas tornam as teorias epistemológicas mais plausíveis, mas também que a ausência de tais exigências acaba criando problemas muito difíceis, como o assim chamado "problema do conhecimento fácil".

PALAVRAS-CHAVE - Infinitismo. Problema do critério. Metajustificação. Conhecimento. Metaconhecimento. Ceticismo.
ABSTRACT - This essay discusses the Problem of the Criterion, one of the most important problems in Epistemology. The answer given to this problem will shape a fundamental aspect of theories of knowledge. It also analyzes some of the consequences epistemological theories may face in accepting metaepistemological requirements. These consequences are given special consideration with regard to Infinitism, the epistemological theory according to which the reasons that support our beliefs must be infinite and non-repeating. Finally, this essay claims not only that those propositions that require metajustification make any theory, even Infinitism, more plausible, but also that the absence of such requirements creates difficult problems, such as the so-called "Problem of Easy Knowledge."

KEY WORDS - Infinitism. Problem of the Criterion. Metajustification. Knowledge. Metaknowledge. Skepticism.

The Problem of the Criterion (PC) leaves us grappling with a very complicated question: should we think that knowing that one knows is a condition of knowing in the first place? This question can be posed in different ways: must a theory state that to know that an evidence or reason is adequate is part of what is necessary to be justified in believing some proposition on the basis of that evidence or reason? Or, still, is it right to claim that we can come to know some proposition $\mathrm{p}$

* Research fellow. FAPERGS (Fundação de Amparo à Pesquisa do Rio Grande do Sul).

\begin{tabular}{|l|l|l|l|l|l|}
\hline VERITAS & Porto Alegre & v. 50 & n. 4 & Dezembro 2005 & p. 109-128 \\
\hline
\end{tabular}


on the basis of having arrived at $\mathrm{p}$ through a reliable process of belief formation without knowing that the process is in fact reliable? ${ }^{1}$

As Chisholm described it once, the PC consists of having to make a special kind of decision, "how do we decide, in any particular case, whether we have a genuine item of knowledge?" ${ }^{2}$ Of course, those are epistemic decisions, since they are about deciding whether we know that we know something. As a result, the PC must be defined as a metaepistemological problem. With that in mind, for present purposes, it will prove useful to call the PC a "metaepistemological problem" (departing somewhat from the conventional use of the adjective "metaepistemological").

There are two obvious ways in which we can deal with the PC. On the one hand, we might say that the PC is only about second-order knowledge. ${ }^{3}$ In this sense, granting that we have first-order knowledge, we should only try to find out if we know that we have this piece of first-order knowledge. An eventual failure to know that we know would have no impact on our first-order knowledge. In this case, the situation in which $\mathrm{S}$ knows that some proposition $\mathrm{p}$ is true, but fails to know that he knows $\mathrm{p}$ is true, would be unproblematic.

On the other hand, we might say that the claim underlying the PC states that in order to have first-order knowledge we must know that we know. Then, in order to know that some proposition $\mathrm{p}$ is true, we will have to know that the reason on which our believing that $\mathrm{p}$ is based is adequate, or that the process of belief formation of $\mathrm{p}$ is reliable. Otherwise, we would be missing some fundamental point regarding the phenomenon of knowledge. To use an expression from Sextus Empiricus, lacking this second-order knowledge will make us so vulnerable to criticism that we would be discredited.

In one sense, then, we could claim that, since the PC has this metaepistemological nature, the question is not about whether we know something - i.e. it is not about first-order knowledge - but only about whether we know that we know something - i.e. it is only about second-order or metaknowledge. Yet, under another interpretation, we could say that the metaepistemological nature of the PC makes it a problem about whether we know something, because failing to know that we know would have a negative impact on our first-order knowledge. In this last sense, the PC would point to the existence of a natural and resilient bridge between knowing and knowing that one knows.

\footnotetext{
For ease of exposition, I will speak about knowledge of reliability as if it amounted to knowing that one knows. I am assuming that to know that a process is reliable is equivalent to knowing that one knows. In the same way, I will assume that knowing that an evidence or reason is adequate is also equivalent to knowing that one knows.

2 Chisholm, Roderick, The Foundations of Knowing, (University of Minnesota Press, Minneapolis, 1983), p.62.

3 I will take the expression "second-order knowledge" and "metaknowledge" as synonymous with "knowing that one knows".
} 
According to the theories that deny that we have to know that we know in order to know in the first place, the phenomenon of knowledge can be understood and completely captured in the absence of second-order knowledge. Thus, a person $\mathrm{S}$ should be granted knowledge that $\mathrm{p}$ if, for example, he believes a true proposition $\mathrm{p}$ and uses a reliable process of belief formation, without having to know that the process is in fact reliable. But, according to the other way to deal with the PC, if $\mathrm{S}$ has a true belief that $\mathrm{p}$, and this belief is a result from what is, unbeknownst to $\mathrm{S}$, a reliable process of belief formation, $\mathrm{S}$ could be seen, from some point of view (naturally, not the point of view of $\mathrm{S}$ himself), as avoiding an accidentally true belief. But if $\mathrm{S}$ did not know that the process was reliable, $\mathrm{S}$ would be missing something epistemically decisive. In the absence of secondorder knowledge, what S has doesn't amount to much at all.

Following Stewart Cohen's suggestion, we may call the theories that claim that we can come to know that $\mathrm{p}$ is true without knowing that we know p, "Basic knowledge structure theories" (BKT). Also, we may call the first-order knowledge acquired without metaknowledge "Basic knowledge" (BK). According to Cohen,

$\mathrm{S}$ has basic knowledge of $\mathrm{P}$ just in case $\mathrm{S}$ knows $\mathrm{P}$ prior to knowing that the cognitive source of S's knowing P is reliable. Our knowledge has basic knowledge structure just in case we have basic knowledge and we come to know our faculties are reliable on the basis of our basic knowledge.

The BKT permit, then, that a knowledge source "can deliver knowledge prior to one's knowing that the source is reliable" and "hold that reliability knowledge is based on basic knowledge". ${ }^{\circ}$

Before proceeding, I want to clarify a couple of things about the vocabulary Cohen uses. First, the idea of "knowledge source" can be seen as indicating two things: a knowledge source could be a method of belief formation, as well as the reason that is supposed to justify some particular belief. I think this is what Cohen means. Moreover, we must bear in mind that "reliability knowledge" is equivalent to metaknowledge, in the sense that, when one gets knowledge of the reliability of a knowledge source, one knows that one knows.

In light of these last clarifications, the point is this: if the BKT hold that metaknowledge can be based on basic knowledge there would be a decisive reason to abandon those theories. The threat faced by BKT is what has been called "bootstrapping". I will not discuss this problem in great detail, but I do want to clarify what "bootstrapping" means.

Cohen, Stewart, "Why Basic Knowledge is Easy Knowledge", Philosophy and Phenomenological Research, 2005, p. 417.

Cohen, Stewart, "Basic Knowledge and the problem of Easy Knowledge", Philosophy and Phenomenological Research, 2002, p. 310.

6 Cohen, Stewart (2002, p. 311)

According to Cohen, the BKT will face what he called the "Problem of Easy Knowledge", and Bootstrapping would be one way to raise this problem. The other way would be the Closure Principle. I will not consider the problem that supposedly arises from the Closure Principle. The main reason for that is that the sort of knowledge easily acquired by Closure does not seem to be second- 
We can think of bootstrapping through the following example. ${ }^{8}$ Suppose that a person, Michael, is driving his car from California to Alaska. Soon after he passes a gas station, he reads a road sign that says that the next gas station will be 300 miles away. Then, he looks at the car's gas gauge and comes to believe (1) the tank is full. According to a BKT like Reliabilism, this belief is an item of knowledge for Michael, provided that (a) it is true that the tank is full and (b) the gauge is reliable - both of which we can suppose for the sake of the argument. Using the terms just defined, Michael has BK that (1). So, according to Reliabilism, even if Michael does not know that he knows the tank is full or that the gas gauge is reliable, his belief that the tank is full is an item of knowledge for him.

A bit later, seeing that it is getting dark and cold out there, Michael checks the gas gauge again. Now, he comes to believe (2) the gauge marks "full." According to a BKT, (2) is also an item of Michael's knowledge, provided that it is true that the gauge marks "full" and that Michael's vision is reliable - which we can also suppose for the sake of the argument. Again, Michael doesn't know that he knows (2), but he knows the gauge marks "full." Once again, Michael has BK that (2).

At this moment, Michael can believe (3) the gauge marks "full" and the tank is full. From any point of view, Michael is entitled to infer (3) from (1) and (2). Actually, since Michael comes to believe (3) deducting it from (1) and (2), Michael knows (3), given that deduction is a reliable process of belief formation. I will insist on one point, since it seems very important: Michael doesn't know that he in fact knows (1) or (2), but according to the BKT, unbeknownst to him, he knows (1) and (2), and once he deduces (3) from (1) and (2), he knows (3) as well.

Here is where the Bootstrapping comes in: since Michael knows (3), nothing prevents him from inferring from (3), (4) the gauge is working properly on this occasion. Since the example I am offering is quite similar to Vogel's example, and given how crucial this step is, it seems useful to see exactly what he says.

So, for example, when the gauge reads ' $F$ ' she believes that, on this occasion, the tank is full. She also believes that, on this occasion, the gauge reads ' $F$ '. Moreover, Roxanne combines these beliefs; she believes: (20) On this occasion, the gauge reads 'F' and F.

order knowledge. This means that the resolution of that "version" of the Problem of Easy Knowledge should be completely different from the Bootstrapping problem. By the way, I think the analysis provided by Klein in "Closure Matters: academic skepticism and easy knowledge" Philosophical Issues, 2004, is essentially correct. As far as I understand, the entire problem hinges on deciding under which circumstances it would be right to reason from "the table next to me seems red" to "the table next to me is red", and not on the reasoning that involves the Closure Principle, that would go from "the table next to me is red" to "the table next to me is not white but illuminated by red lights". Then, what the Problem of easy knowledge calls for is an analysis of that first way of reasoning. As Klein suggested, much can be resolved with the idea according to which the Closure Principle does not specify a priority among reasons and, then, the reason available to believe that the table is red need not be the same reason to believe that the table is not white but illuminated by red lights. Anyway, I will not take into account in what follows the questions that involve the Closure Principle.

8 I will try offering an example similar to Jonathan Vogel's in "Reliabilism Leveled", Journal of Philosophy, 2000. 
Certainly, the perceptual process by which Roxanne forms her belief that the gauge reads ' $\mathrm{F}$ ' is a reliable one. By hypothesis, her belief that the tank is full is also reached by a reliable process. Hence, there seems to be no good reason to deny that Roxanne's belief in (20) is the result of a reliable process, and the reliabilist will say that she knows (20). Now, it is a completely straightforward logical consequence of (20) that:

(21) On this occasion, the gauge is reading accurately. Assume that Roxanne deduces

(21) from (22). Deduction is certainly a reliable process, so there is no loss of reliability at this step. Consequently, it seems that Roxanne must be credited with knowing (21). ${ }^{9}$

Going back to our example, the decisive step is when Michael comes to know the gauge is reading accurately on some occasion based on his knowledge of (3) (the gauge marks "full" and the tank is full). Furthermore, if Michael repeats this same procedure and makes a few inductive inferences, he can then come to know that the gauge is working properly. ${ }^{10}$ As we have seen, (3) is based on Michael's basic knowledge of (1) and (2). So - without forgetting the inductive step - we can claim that reliability knowledge is being based on basic knowledge.

Now, what would be the problem if Michael comes to believe (4) the gauge is working properly on some particular occasion? In a certain sense, there is no problem at all, as long as Michael infers (4) from (3). However, the point is that with (4) Michael suddenly comes to know that he knows the tank is full, since (a) knowing that the gauge is working properly is equivalent to reliability knowledge ${ }^{11}$ and (b) reliability knowledge is equivalent to knowing that one knows. The problem for BKT, then, is that the description of Michael's acquisition of second-order knowledge is in perfect accord with a BKT like Reliabilism, but this acquisition of second-order knowledge cannot be considered legitimate. So, this way of acquiring metaknowledge may be seen as a reductio of all BKT's.

In our example, Michael is basing reliability knowledge on basic knowledge. Since it is not only Reliabilism that holds that reliability knowledge is based on basic knowledge, the problem must be in the feature of all BKT's that is shared by Reliabilism. The problem is that we cannot come to know that we know in this way, but this way of acquiring metaknowledge is approved by any BKT. So, we have a problem with BKT in general.

Vogel, Jonathan, "Reliabilism Leveled", The Journal of Philosophy, 2000, p. 615.

There is something tricky here. One may easily overlook the difference between "reading accurately" and "working properly." We should bear in mind that knowing that "the gauge is reading accurately" is not really the same as knowing that "the gauge is working properly," since it is possible that the gauge reads accurately on some occasions even when it is broken-i.e. the gauge can accidentally read accurately.

11 In fact, Michael would need more inferences in order to make an inductive inference that the gauge is reliable on all occasions. However, those are ancillary inferences that will present no problem to this kind of analysis. All he would need is to make more inferences of the same type: "now, the gauge is working well," and after a certain amount of inferences of this kind, he would be able to conclude that the gauge is working properly all the time. 
We must note also that, as was pointed out by Cohen, ${ }^{12}$ not only Externalist theories, like Reliabilism, are BKT, and thus face the Problem of Bootstrapping. On the contrary, as we will see, many Internalist theories, like Infinitism, can be BKT's as well.

In what follows, I shall assume that BKT's cannot provide a comprehensive analysis of knowledge or justification, since all BKT face the Bootstrapping Problem. In turn, the most important point is that the Bootstrapping Problem derives from a misdirected description of the condition for first-order knowledge or justification. Hence, we cannot separate epistemic levels, and we have to analyze the phenomenon of knowledge in a way that combines knowing and knowing that one knows.

\section{Infinitism}

Infinitism is preferable to both Coherentism and Foundationalism, mainly in light of the fact that Infinitism is the only theory capable of avoiding dogmatism as well as circularity. I am not going to defend Infinitism over Foundationalism and Coherentism, though. I agree with Klein that no criticism against Infinitism does succeed. ${ }^{13}$

However, I want to take into account a particular feature of Klein's Infinitism and try to suggest that it must (and can) be changed in order for Infinitism to be transformed into a more compelling theory. The aspect of Infinitism I will treat is directly related to that which is responsible for making some theory a BKT.

According to Klein, a person S will have justification to believe some proposition $\mathrm{p}$ if $\mathrm{S}$ has reasons available to him. This is what the Principle of Avoiding Arbitrariness states,

(PAA) For all $\mathrm{x}$, if a person, $\mathrm{S}$, has a justification for $\mathrm{x}$, then there is some reason, $\mathrm{r} 1$, available to $\mathrm{S}$ for $\mathrm{X}$, and there is some reason, $\mathrm{r}$, available to $\mathrm{S}$ for $\mathrm{r} 1$, etc, and there is no last reason in the series. ${ }^{14}$

The notion of availability has two different aspects, one subjective and another objective. In spite of the relevance that subjective availability has for Infinitism, we can put this notion aside. What is crucial for our purposes here is the idea according to which a reason must be objectively available for $\mathrm{S}$.

The conception that a reason must be objectively available to some person $\mathrm{S}$ shows that not just any proposition will be a reason for $\mathrm{S}$ to believe some other proposition. It means that the reason $r$ must be adequate from some objective perspective. Furthermore, by granting that not any proposition can be a proper justifier, Infinitism need not produce a particular account of objective availability.

12 This point was also made by Bergman, Michael, "Externalism and Skepticism", The Philosophical Review, 2000.

3 For example Klein, Peter, "When Infinite Regresses Are Not Vicious", Philosophy and Phenomenological Research, 2003, p 728.

14 Klein, Peter (2003, p 728). 
As Klein says, "there are many accounts of objective availability. Each specifies either some normative or non-normative properties or, perhaps, a mixed property that is sufficient to convert a belief into a reason". "We could think of these accounts of objective availability in this way,

One could say that a belief, $r$, is objectively available to $S$ as a reason for $p$ if (1) $r$ has some sufficiently high probability and the conditional probability of $\mathrm{p}$ given $\mathrm{r}$ is sufficiently high; or (2) an impartial, informed observer would accept $r$ as a reason for $\mathrm{p}$; or (3) r would be accepted in the long run by an appropriately defined set of people; or (4) $\mathrm{r}$ is evident for $\mathrm{S}$ and $\mathrm{r}$ makes $\mathrm{p}$ evident for $\mathrm{S}$; or (5) r accords with S's deepest epistemic commitments; or (6) r meets the appropriate conversational presuppositions; or (7) an intellectually virtuous person would advance $r$ as a reason for $\mathrm{p}^{16}$

By itself, this aspect doesn't subject Infinitism to the Bootstrapping Problem. As we know, the requirement of objective availability is quite common in almost all theories of knowledge or justification. The aspect I want to point out is the idea according to which $\mathrm{S}$ is not supposed to be justified that $\mathrm{r}$ is objectively available to him in order for $\mathrm{S}$ to have justification to believe $\mathrm{p}$ on the basis of $\mathrm{r}$. Actually, for Klein, S need not have either (a) a belief that $\mathrm{r}$ is an objectively available reason for believing $\mathrm{p}$, or (b) have justification - without believing - that $\mathrm{r}$ is objectively available to S. According to Klein, all that matters is the objective property that $\mathrm{r}$ must have in order for $\mathrm{S}$ to have justification to believe $\mathrm{p}$ on the basis of $\mathrm{r}$.

In a footnote to "Human knowledge and infinite regress of reasons," Klein says,

Let me make the distinction between the three views of justification absolutely clear. The 'thin' view (the one I think is correct) holds that $S$ has a justification for $p$ on the basis of $r$ entails that (a) $S$ believes $r$ and (b) $r$ is reason for $p$. It does not require that, in addition, either (1) $\mathrm{S}$ believes that $\mathrm{r}$ is a reason for $\mathrm{p}$ or (2) $\mathrm{S}$ is justified in believing that $r$ is a reason for $p$. The 'moderately thick view' (the one I think is plausible) adds

(1) to the thin view. The 'extremely thick view' (the one I think cannot be correct) adds

(2) and presumably (1) as well to the thin view. ${ }^{17}$

Klein still adds, "I think it is the reason available to $S$ for $p$ that determines whether $\mathrm{S}$ has a justification for p regardless of S's beliefs about those reasons." 18 This characteristic of Infinitism, or of any kind of Internalism, is what makes it a BKT.

It is quite important to make some distinctions here. First of all, no plausible theory would deny the possibility of acquiring second-order knowledge, or deny the possibility for some person $\mathrm{S}$ to have justification that he has justification to believe some proposition $\mathrm{p}$. The point is whether we will consider the metaepistemic requirement a necessary condition to be justified in the first place. Second,

15 Klein, Peter, "Human Knowledge and the infinite regress of reasons", Philosophical Perspectives, 1999, p. 299

Klein, Peter, (1999, p. 299)

17 Klein, Peter, (1999, p. 322)

18 Klein, Peter, (1999, p. 322) 
there is a difference between (a) requiring a belief according to which a reason $r$ is a good or adequate reason to believe $\mathrm{p}$, and (b) requiring justification to believe that a reason $r$ is a good or adequate reason to believe $p$.

At the outset, it seems that what subjects a theory to the Bootstrapping Problem is not related to believing itself. What matters is justification only. Hence, Infinitism couldn't be made invulnerable to the Bootstrapping Problem if it required that $\mathrm{S}$ must believe, or must have some disposition to believe, that $\mathrm{r}$ is the reason for believing $p$. Therefore, even Klein's "moderately thick view" wouldn't keep Infinitism from being a BKT. What may prevent a theory from being a BKT is the need to name the epistemic efficiency of what justifies some belief.

We could say, then, that the BKT could be avoided either with (a) the requirement that $\mathrm{S}$ needs to have justification for believing that $\mathrm{r}$ is objectively available to $\mathrm{S}$, or (b) the requirement that $\mathrm{S}$ needs a justified belief that $\mathrm{r}$ is objectively available to him. I think (a) is more adequate, because it seems enough to keep a theory from being a BKT, although not as demanding as (b), since (a) doesn't require an act of believing.

Demanding the identification of the reason that is being used in believing $p$ does not prevent the Bootstrapping Problem, because the mere identification of the reason is not enough to avoid a question that resides precisely in our capacity to identify the epistemic efficacy of our reasons. Undoubtedly, identifying the reason used - which also goes for the method of belief formation - is a necessary condition, since we couldn't have justification, or a justified belief, that the reason $r$ is objectively available if we are not aware of which reason, or method, is being used to support some particular belief $\mathrm{p}$. What is required to avoid the Bootstrapping Problem is some justification for a belief about the epistemic effectiveness of the reasons we use to hold some particular belief $\mathrm{p}$. Therefore, in order to avoid Bootstrapping, we would have to uphold the two first conditions offered by Klein, namely, (1) $\mathrm{S}$ believes $\mathrm{r}$ and (2) $\mathrm{r}$ is a [objectively available] reason for $\mathrm{p}$, but add that $\mathrm{S}$ must have justification to believe that the reason $\mathrm{r}$ is objectively available to him - provided this last condition implies that $\mathrm{S}$ is capable of identifying the reasons he actually uses for believing $\mathrm{p}$.

If the absence of a requirement according to which $\mathrm{S}$ would need to have justification to believe that the reason $\mathrm{r}$ is objectively available to him in order to have justification to believe $\mathrm{p}$ on the basis of $\mathrm{r}$ correctly depicts Klein's proposal, then Infinitism should be characterized as a BKT. Any BKT will deny that we have to have justification that our reason to believe $\mathrm{p}$ really does justify $\mathrm{p}$ in order to have justification to believe $\mathrm{p}$ on the basis of that reason in the first place. Infinitism, having the basic knowledge structure, allows that a reason r, being objectively available, grants justification to $\mathrm{S}$ before $\mathrm{S}$ knows that $\mathrm{r}$ is objectively available to him. Then, S could know $\mathrm{p}$ without knowing that he knows p. (Granted, $\mathrm{S}$ could come to know that he knows $\mathrm{p}$ if $\mathrm{S}$ knows that $\mathrm{r}$ is an appropriate reason to believe $\mathrm{p}$ ). 
Infinitism allows for basic knowledge in the same way Reliabilism does. As we can see, in this respect Infinitism is identical to Reliabilism. In fact, the only difference between them is that, with regard to Infinitism, we will talk about the objective availability of some reason, and with regard to Reliabilism, we will talk about the reliability of some belief formation process instead. Nonetheless, this difference is just not of consequence. What is central to both these theories is the absence of epistemic priority of second-order knowledge over first-order knowledge. Consequently, Reliabilism as well as Infinitism allow for BK and then permit the acquisition of metaknowledge on the basis of BK.

Basing knowledge of the reliability of a process on a belief that results from that same process must be equivalent to using a belief $\mathrm{p}$ which is objectively justified by reason $r$ to show that $r$ is an objectively available reason to believe $\mathrm{p}$. In both cases, what we have is the same: basic knowledge illegitimately generating metaknowledge. Again, what makes this possible is that it is not necessary for $\mathrm{S}$ to have some justification to believe that $\mathrm{r}$ is an objectively available reason to believe $\mathrm{p}$ in order to have justification to believe $\mathrm{p}$ on the basis of $\mathrm{r}$ in the first place. Whenever we are dealing with the reliability of a belief formation process, we could bootstrap in order to come to know that the process is reliable; whenever we talk about reasons, we could bootstrap in order to come to know that we have objectively available reasons for our beliefs. In both cases, the problem resides in the inadequacy of the constraints that are placed upon what is a necessary condition for having justification for believing some proposition in the first place. In both cases, concerning reliability and objective availability, S will be able to use his BK in order to show that the reason he uses to justify his beliefs is in fact appropriate, exactly because it is not required of $\mathrm{S}$ that he have independent justification to believe that his reason is adequate. In other words, the problem is that just using a reliable method, or just having an objectively available reason, is not enough to have justification for believing in the first place.

Suppose, for example, that a person, Pedro, believes (1) a snowstorm is likely in Montana, and that the reason Pedro has to believe (1) is that (2) dark clouds are gathering over the mountains and it is mid-winter in Montana. ${ }^{19}$ Let us suppose that (2) is objectively available for Pedro, but that he doesn't know that (2) is adequate to justify his belief in (1). Accordingly, Pedro may know that a snowstorm is likely, provided that (a) (1) is true; (b) he uses (2) to base his belief in (1) and (c) (2) is an objective available reason for believing (1). However, since he doesn't know (c), he doesn't know that he knows (1). So, if Pedro believes (1), this belief will be, unbeknownst to him, an item of knowledge - a BK - for him.

If the description above is compatible with Infinitism, Infinitism cannot prevent Pedro from using his BK to come to know that he knows that a snowstorm is likely. This situation is analogous to the gas gauge example: if Pedro believes (1), and his belief in (1) is supported by (2), then Pedro knows (1). If Pedro doesn't

19 This example was used by Klein to show what would be an objectively available reason in "Human knowledge and the infinite regress of reasons". 
know that (2) is adequate to justify (1), Pedro has BK of (1). Yet Pedro must be capable of identifying that (2) is being used to justify (1). ${ }^{20}$ So, once he knows (1) and realizes that (1) is based on (2), Pedro can believe (3) a snowstorm is likely and dark clouds are gathering over the mountains and it is mid-winter in Montana.

Now, nothing prevents Pedro from, on the basis of (3), coming to believe (4) that dark clouds are gathering over the mountains and it is mid-winter in Montana is an appropriate reason to believe that a snowstorm is likely. This is possible because Pedro, according to Infinitism, knows (1), and, by introspection, knows that (1) is based on (2).

As was the case with the gas gauge example, I think it would be useful to see what exactly Cohen writes about it,

In fact, the problem of bootstrapping generalizes to evidentialist theory as well. That is, it generalizes to any evidentialist theory that allows for basic knowledge. [...] Consider evidentialist foundationalism: according to that view, I can know the table is red on the basis of its looking red, even though I have no prior evidence that something's looking red is a reliable indication that it is red. But once I know the table is red, I can appeal to that fact in reasoning. A little introspection will tell me that the table appears red. So now I know that the table looks red and that it is red. So now I have some evidence that something's looking red is a reliable indication that it is red. And by taking a few more looks, I can acquire more evidence. ${ }^{21}$

It is important to be clear about this: a BKT, as Infinitism, must concede that Pedro knows two things: (A) his belief that a snowstorm is likely is based on his belief that dark clouds are gathering over the mountains and it is midwinter in Montana, and (B) a snowstorm is likely. In other words, he knows that a snowstorm is likely and knows why he believes so, even though he doesn't know that he knows that a snowstorm is likely, i.e. even though he doesn't know that (2) is appropriate to justify (1). In this circumstance, since Pedro knows (A) and (B), nothing can prevent him from believing that (4) dark clouds are gathering over the mountains and it is mid-winter in Montana is an appropriate reason to believe that a snowstorm is likely. Now, (4) is equivalent to knowing that one knows that a snowstorm is likely, given that knowing that the reason to believe (1) is appropriate is equivalent to knowing that one knows (1).

In this case, Pedro suddenly knows that he knows that a snowstorm is likely, since he now knows that his reason, namely (2), is adequate to justify his believing (1). This means that the absence of a requirement according to which Pedro needs to have a reason to believe that (2) is adequate for believing (1) in order to have justification for believing (1) in the first place makes it possible for Pedro to know that he knows (1) in a way that cannot be legitimate.

\footnotetext{
${ }^{20}$ It would be very odd to require that Pedro must have justification for believing (2), and that his believing (2) has to have a causal role in believing (1), if Pedro has a justified belief that (1) without his being at least capable of identifying (2) as his reason to believe (1).

Cohen, Stewart, (2002, p.318)
} 
What is crucial here is that given that Pedro may identify (2) as the reason to believe (1), even without any independent reason to believe that (2) is appropriate to justify (1), if Pedro introspects a little he may find an illegitimate way to believe that (2) is appropriate to justify (1), and then, appears as if knowing that he knows (1).

What happens to Infinitism is the same that happens to Reliabilism: there is no sufficient constraint about what is necessary to have justification to believe in the first place. This way to get second-order knowledge or justification is illegitimate only because the way to get first-order knowledge, even though it may not seem wrong from some perspective, cannot be right. The problem with this second-order knowledge acquisition derives from too lax a set of conditions for firstorder knowledge.

I am quite sure that there are various ways to manifest dissatisfaction with the restrictions that concern a requirement of metajustification. Take, for instance, Lehrer's appraisal,

Examples of alleged knowledge in which a person does not know that the information he accepts is correct may be of some philosophical interest but such knowledge falls outside the concern of knowledge used in a way that is characteristically human in critical reasoning and the life of reason. ${ }^{22}$

In some sense, the Bootstrapping Problem can be seen as demonstrative of what is wrong with the sense of "knowledge" that results when one ignores whether the information accepted is correct - or ignores that a reason is objectively available, or that a process is reliable. Therefore, the Bootstrapping Problem just helps to establish a very welcome result for epistemology: no theory of knowledge can claim that a person S knows p without knowing that he knows p.

\section{Avoiding The Bootstrapping Problem}

If the previous diagnosis is right, it is not too difficult to see what kind of change must be made in order to eliminate the threat of the Bootstrapping Problem. The idea consists of reestablishing the epistemic priority of second-order knowledge. If the root of the Bootstrapping Problem grows from an unbalanced relation between first and second-order knowledge, all we have to do is bring proper equilibrium to this relationship. The point, then, is just to realize that we cannot separate knowing from knowing that one knows, and find a way to keep them adequately related. However, to accept that we cannot separate epistemic levels will be much simpler than to explain how exactly we must relate them.

Focusing only on what matters most to our present concerns, it must be made clear that to keep the levels adequately related means that we will have to claim that in order to have justification to believe some proposition $\mathrm{p}$ on the basis of some reason $r$, one has to have justification to believe that $r$ is a proper justifier for $\mathrm{p}$. This means that we will have to have metajustification for believing $\mathrm{p}$. Or, in

22 Lehrer, Keith, Theory of Knowledge (Westview Press, Boulder, 2000). p. 41. My emphasis. 
other words, if we have justification to believe some proposition $p$, because $p$ results from a reliable method of belief formation $\mathrm{m}$, then it must be the case that we have justification to believe that method $m$ is reliable. This sort of metajustification requirement will make any theory immune to the Bootstrapping Problem.

Before proceeding, let us further clarify the idea of "metajustification" or "metaepistemic requirement." As it will be understood here, a metajustification must be directed toward some particular belief. Thus, in the same way we can ask for justification for the belief that $\mathrm{p}$, we can ask for metajustification for the belief that $\mathrm{p}$. Justification for believing $\mathrm{p}$ involves the reasons we have to believe that some proposition is true; metajustification concerns our reason to believe that the reason we have for believing that $p$ adequately justifies our belief that $p$. Let us use an example to clarify how the metajustification requirement may work. Suppose that I believe that people from Angola speak Portuguese, and suppose that my justification to believe that it is true that people in Angola speak Portuguese consists of the following reason: Angola was colonized by Portugal. The metajustification to believe that people from Angola speak Portuguese will consist of my justification to believe that my reason, namely that Angola was colonized by Portugal, really justifies my belief that people from Angola speak Portuguese. It could be something like "colonies inherit the language of their colonizers." My metajustification to believe that people from Angola speak Portuguese consists of my justification to believe that my reason, that Angola was colonized by Portugal, is effective in justifying my belief that in Angola people speak Portuguese, and the proposition "colonies inherit the language of their colonizers" plays this role.

As you may have noticed, there is a potential problem lurking around here. I will come back to it later.

In principle, there are many different ways to describe what it is that could make any theory bulletproof against Bootstrapping. My own suggestion is that, in conjunction with the objective conditions for justification proposed by Klein, we will have to add something along the lines of the second clause of Fumerton's Principle of Inferential Justification (PIJ): to be justified in believing one proposition $\mathrm{P}$, on the basis of another proposition $\mathrm{E}$, one must be (1) justified in believing $\mathrm{E}$ and (2) justified in believing that $\mathrm{E}$ makes probable $\mathrm{P}^{23}$

Discussing the PIJ will lead us to consider two important points that are involved in the metajustification requirement and, as long as we make the necessary clarifications, we can deal with those two points.

One important clarification has to do with the very terms in which Fumerton expresses the second clause of the PIJ. I don't think it is necessary - for our purposes here, at least - to understand the second clause of the principle including the specific content Fumerton holds is the right one to make $r$ a justifier for $\mathrm{p}$, namely the idea according to which $r$ makes probable $\mathrm{p}$. We can just leave open the possibility that that which makes $r$ a justifier for $\mathrm{p}$ need not be defined as a probabilistic

23 Fumerton, Richard, Metaepistemology and Skepticism (Rowman and Littlefield Publishers, 1995), p. 36. I think clause (1) is not problematic and it is contained in Klein's conditions discussed above. 
relation between $r$ and $p$, and substitute "r makes probable $p$ " for " $r$ justifies $p . "$ I don't think it would be wrong, in a preliminary analysis, to interpret the second clause of the PIJ as, "in order to have justification for believing $\mathrm{p}$ on the basis of $r$, or method $\mathrm{m}$, one must have justification to believe that $\mathrm{r}$ justifies $\mathrm{p}$, or that the method $m$ is reliable."

Furthermore, we should read the PIJ as stating that one has to have justification for believing, but not necessarily a justified belief, that the reasons are adequate or the processes are reliable. Since having justification is enough to avoid the Bootstrapping Problem, we don't need a justified belief to make any theory invulnerable to the problem.

We can now deal with the following points. The first point has to do with the idea that accepting a principle like the PIJ, or any other principle that states the necessity of a metaepistemic requirement, implies being committed to some form of "level confusion".

I am not quite sure about the best way of characterizing a level confusion. If to state some relation between the levels, particularly the relation according to which we cannot be justified in the first place without having justification for the belief that we have justification, implies confusing epistemic levels, then the second clause of the PIJ - and, in fact, any metaepistemic requirement - confuses epistemic levels.

However, one could hardly say that any such thing is, per se, a case of level confusion. Actually, talking about justification without making some necessary distinctions is exactly what seems to be at the core of level confusion. A case of level confusion would be the result of the absence of a clear distinction between having justification to believe $\mathrm{p}$ and having metajustification to believe $\mathrm{p}$. The failure to keep this distinction clear seems to me a more correct way to characterize level confusion.

The pivotal problem with the acceptance of the second clause of the PIJ, though, is that it would generate an infinite metaregress: "[I]f finite minds should worry about the possibility of completing one infinitely long chain of reasoning, they should be downright depressed about the possibility of completing an infinite number of infinitely long chains of reasons" ${ }^{25}$ The point, then, is that the idea of completing an infinite number of infinitely long chains of reasoning cannot be claimed as a necessary condition to be justified in believing any proposition, since it is just impossible to complete any such infinite chain.

The criticism against Infinitism seems to take, then, two forms: one concerns the first-order regress, and refers to the necessity of completing one infinite chain of reasoning, to which I will refer here as one infinity. The other concerns the second-order regress, or metaregress, and refers to completing not just one, but an infinite number of infinite chains of reasoning, to which I will refer here as infinite infinities.

24 Huemer, Mike, "Fumerton's Principle of Inferential Justification", Journal of Philosophical Research, 2002.

Fumerton, Richard, (1995, p. 57) 
Now it is necessary to identify what exactly is the problem that could afflict Infinitism. Although it may be a platitude to say that not every infinite series or regress is a vicious one, it seems appropriate to insist on it. Just to remember a single example,

A well-known example of a 'benign' regress is the so-called 'truth regress.' This regress, which can be derived simply from the Tarsky schema and plausible ancillary assumptions about what are fit substitutions into the schema, demonstrates that there are an infinite number of truths corresponding to each truth. For, as is commonly known, where $p$ is some proposition, if $p$ is true, then ' $p$ is true' is true, as is " $p$ is true' is true' is true, and so on. ${ }^{26}$

So, I cannot agree with the claim that an infinite regress or series is vicious only because of the fact that it is infinite. There must be something more than the mere property of being infinite that makes a particular series, chain, or regress a vicious one. Hence, the mere existence of some infinite series or regress cannot counts as a reductio of Infinitism. On the contrary, I will assume that, in order to constitute a refutation, it must be shown why some particular infinite series, chain, or regress is vicious.

However, the idea of completing an infinite chain of reasoning does point to what will make Infinitism an implausible theory. Accordingly, Infinitism would seem to imply that a person would have to have infinite beliefs in order to have a single justified belief. More precisely, one would have to have infinite beliefs in order to have a single justified belief. In this idea, apparently, would reside Infinitism's most serious problem.

Now, as far as I can see, this supposed problem is not necessarily related to the metaregress. The impossibility of completing an infinite number of infinite chains of reasoning is the very same problem we would find if we considered only the firstorder regress, i.e. considering only the impossibility of completing one infinite chain of reasoning. To be clear, if the criticism against Infinitism is grounded on the idea that no human being is capable of completing one infinite chain of reasoning, then it is just unnecessary to add infinite infinities to the criticism, since just one infinity is enough to make the point. In fact, there cannot exist any difference between the impossibility of completion of one infinity and infinite infinities. Nothing can become more impossible to complete than one infinity, and talking about infinite infinities will just repeat the same point. So, the difference between first and second-order regress is irrelevant to this criticism, since it does not depend in any way on the metaregress, i.e. it does not depend on infinite infinities. Therefore, I do not agree that there is a difference regarding problems posed by one infinity - the first-order regress - that according to Fumerton may makes us "worried," and problems posed by infinite infinities - the metaregress - that would make us not only worried, but "downright depressed." Actually, both present the same problem and, as far as I can see, if we were supposed to complete one infinite chain of reasoning, we should be downright depressed from the very beginning.

${ }^{26}$ Nolan, Daniel, "What's Wrong With Infinite Regresses?", Metaphilosophy, 2001, p. 524. 
If this is right, there should be no problem on the second-level, as long as there is no problem on the first-level. So, if Infinitism correctly deals with the firstorder regress, as I think it does, we have got a reason at least to suspect that Infinitism may provide a correct way to handle this metaregress and, in fact, all kinds of regresses.

I will not focus on the infinitist response to the criticism according to which Infinitism implies that we would have to complete an infinite chain of reasoning. Klein has already shown that line of criticism misrepresents properly formulated infinitist claim. ${ }^{27}$ For present purposes, suffice it to say that, while it is true that no one would be able to complete an infinite chain of reasoning, Infinitism does not claim that this would have to be done. In fact, according to Infinitism, it is not necessary to complete an infinite chain of reasoning in order to have a justified belief.

I just would like to explain a little further why the idea that there must exist an infinite number of reasons available for $S$, if $S$ has justification to believe some proposition $\mathrm{p}$, does not imply that $\mathrm{S}$ will be committed to providing reasons nonstop all the time.

Klein has claimed that sometimes we are just not involved with the process of justification, and because of this, we are not supposed to provide reasons all the time. He must be right about this, although I think the explanation of why we can stop providing reasons and still be considered non-dogmatics is not yet fully developed. ${ }^{28}$ Of course, getting tired, needing to sleep or even dieing, could explain why we sometimes stop providing reasons for our beliefs. ${ }^{29}$ However, claiming this would not explain why we stop providing reasons in a rational or non-dogmatic fashion. So, this sort of suggestion is sufficient to show why we sometimes stop providing reasons, but it is not enough to explain why we can do so in a non-dogmatic way.

I think the best way to give the required explanation is by focusing on the fact that we can stop providing reasons in a non-dogmatic fashion once we eliminate whatever it is that creates a need to provide reasons in the first place. This means that the need to provide reasons - or to create reasons, if it were the case must respect some criterion. As far as I can see, this criterion seems to be that of doubt, which in turn is generated by disagreements, dialectical or in soliloquy. I will not try to offer here a complete explanation of this point, but it is imperative to understand the stopping places of Infinitism in these terms: disagreements create doubts, and doubts generate the need to provide or create reasons. Without disagreement, that is, without doubt, there is no need to provide reasons, but this has nothing to do with the requirement according to which if S has justification to believe some proposition $\mathrm{p}$, then there must be an infinite number of reasons available to him. This means that, when doubt is eliminated, we can rationally stop providing reasons. On the other hand, if we still have doubts about some-

\footnotetext{
27 Klein, Peter, 2003.

I think Klein himself would agree with that.

Klein, Peter, "Human Knowledge and the Infinite Progress of Reasoning". Forthcoming.
} 
thing, we can stop providing reasons at will, but in no way would this manner of stopping avoid dogmatism. It is not rational to stop providing reasons when I am fatigued if a disagreement is taking place, because that which generates the need to provide reasons still persists. On the other hand, I can find a rational stopping place for providing reasons if I no longer find disagreements. Of course, this kind of stopping place is provisional, since the absence of disagreement today does not guarantee an agreement tomorrow. In other words, I have no assurances that a belief that is bedrock to me at present will be a bedrock belief to me in the future. However, this provisional stopping place does not seem either problematic or mysterious, but quite natural indeed. So, we should say that, according to Infinitism, justification is not provisional, but the rational stopping places are.

In any case, the important point is that the same kind of response that will be given to the problem of the impossibility of completing an infinite chain of reasoning when it arises in the first-order regress can be given with respect to the second-order regress, namely, that we are not supposed either to complete an infinite chain of reasoning, to be justified in believing that some proposition is true, or to provide reasons non-stop all the time.

To my mind, the most interesting problem here is that Klein himself has said that the second clause of the PIJ would lead to the rejection of Infinitism: "II]t is easy to see that if this condition [the second clause of the PIJ] were coupled with Infinitism, the consequence would be that any person having a justified belief must have a belief that gets 'so complex' that no human could ever have it". ${ }^{0}$ Then, according to Klein, the acceptance of the second clause of the PIJ would lead to unbearably complex beliefs.

This is interesting for many reasons. I suspect it reveals a blurry relationship between Infinitism and the metaepistemic requirement. While Klein bases the criticism against Foundationalism on the need for metaepistemic justification, he refuses to accept the second clause of the PIJ that just represents one way to pose the metaepistemic requirement.

The criticism presented by Klein against Foundationalism does require metajustification. When Klein asks the foundationalist, "why do you think that the basic proposition b is likely to be true?" and the foundationalist replies, "because b has some property $f$ that makes $b$ autonomously warranted," Klein will insist on asking if this property $f$ is a reason to think that $b$ is likely to be true. ${ }^{31}$ The absence of an answer for that last question entitles Klein to charge this type of Foundationalism with dogmatism. This means that Klein is requiring some metajustification: he is asking why the foundationalist thinks that this property $f$ is adequate to make his belief b justified for him. Moreover, Klein seems to assume that it will be necessary to have this sort of metajustification in order to be justified in believing any proposition in the first place. If this is the case, then it highlights the fact that Infinitism

Klein, Peter, (1999, 309)

31 Klein, Peter, "What IS Wrong with Foundationalism Is That It Cannot Solve the Epistemic Regress Problem", Philosophy and Phenomenological Research, 2004. 
presupposes a metaepistemic requirement, or, in other words, that the absence of metajustification makes Foundationalism a theory that is impossible to uphold in a non-dogmatic way.

This result is not surprising, since the criticism presented by Klein seems to be Pyrrhonian in essence. In fact, we could say that Klein is confronting Foundationalism with the Problem of the Criterion, because his criticism appears to be based on the impossibility of establishing a gap between first and second-order knowledge or justification. While the Pyrrhonians are committed to the view that it is impossible to know something without knowing that one knows, Klein is saying to the Foundationalist that we cannot be rational without having a reason to believe that what justifies our beliefs really does justify them.

The necessity of a metaepistemic requirement would be a very welcome desideratum of Infinitism. However, Klein thinks that the second clause of the PIJ will lead to the rejection of Infinitism by generating unbearably complex beliefs.

But the problem of overcomplexity may be just apparent, and could be resolved with the idea that what is necessary is the existence of an infinite number of adequate reasons that may have different functions, such as reasons to believe $\mathrm{p}$ and reasons to believe that the reasons to believe $\mathrm{p}$ are adequate. This would not be a case of over-complexity, but only a case of availability of reasons with different functions.

Let us use an example to see both how complex our beliefs could become and if we really can have justification without metajustification. Suppose that someone believes that women are inferior to men on the basis of the belief that no woman has ever been president of the United States. What is claimed is that in order to have justification to believe that women are inferior to men, this person would have to have justification for believing that that reason, that no woman has ever been president of the US, really justifies the belief that women are inferior to men.

Let us look closely at this case. If $\mathrm{S}$ believes that women are inferior to men, $\mathrm{S}$ is supposed to have a reason, or reasons, to believe so. It is quite easy to imagine a disagreement about whether women are inferior to men. This situation creates a need to provide reasons, i.e. it inaugurates for $\mathrm{S}$ the process of justification of his belief that women are inferior to men. Then, $\mathrm{S}$ could say that he believes that women are inferior to men because no woman has ever been president of the US. This answer, as I think is clear, will not be enough to settle the matter. What, then, is $\mathrm{S}$ supposed to do after that?

First of all, $\mathrm{S}$ is supposed to have a reason to believe that it is true that no woman has been president of the US. Let us grant that $\mathrm{S}$ does, in fact, have an appropriate reason to believe that no woman has ever been president of the US. Even so, that is obviously not enough to settle the question about women's inferiority. Having a reason to believe that no woman has ever been president of the US would at best (let us suppose) be considered necessary, but by no means sufficient, for a justified belief that women are inferior to men. This is a very important point because it shows that the first clause of the PIJ is not enough to capture what it is that amounts to having justification. What seems to be the case is that $\mathrm{S}$ 
is supposed to answer the following question: why do you think the reason "no woman has ever been president of the US" is in any way appropriate to justify the belief that women are inferior to men? Answering this question is decisive, given that a different reasoning could go: I believe that women are superior to men, and my reason to believe so is precisely that no woman has ever been president of the US. All that matters, again, is answering why S thinks that the reason "no woman has ever been president of the US" is appropriate to justify the belief that women are superior to men.

The required metajustification can be achieved by one's providing a reason about the epistemic effectiveness of "no woman has ever been president of the US" for justifying "women are inferior to men." Now, why do we have to think that this reason will be unbearably complex? I don't think it is, because all S needs is just another reason. This metareason (it will be a metareason if we are considering the belief that women are inferior to men) could be something like "the capacity of being a president determines gender superiority." That would provide what the situation calls for.

Of course, we don't have to think that the regress will be stopped at this point. On the contrary, there is no reason to think that it will. If there is some doubt about the effectiveness of the metareason, $\mathrm{S}$ will have to provide more reasons, if $\mathrm{S}$ has justification for believing that women are inferior to men. The next step would be to provide a reason why $S$ thinks that being president determines gender superiority. But I can see no over-complexity here, since all we need in every step is just more simple reasons. What we have to understand is that the propositions that serve as reasons may have different functions. Then, we will still deal with individual reasons, reasons that play different roles, but not obviously complex enough as to become impossible for a person to grasp.

As long as we are interested in pushing the process of justification further, we would find the same scenario with the same requirements. All we have to require is an infinite number of available reasons, and understand that those reasons may serve different functions: on the one hand, to justify, and, on the other, to serve as metajustification. The proposition that serves as metajustification for some belief will not be more complex than the proposition that serves as a reason to believe that proposition.

This example, I hope, shows that we cannot separate epistemic levels. It shows that no one can be justified in believing that women are inferior to men if one doesn't have metajustification - i.e. if one doesn't have justification to believe that the fact that no woman has ever been president of the US adequately justifies the belief that women are inferior to men. If we don't have justification to believe that our reasons are effective in justifying our beliefs, then we don't have justification at all. The opposite view give us an odd result: $\mathrm{S}$ is justified in believing that women are inferior to men, but $\mathrm{S}$ doesn't need justification to believe that the reason that supports his belief is appropriate! The point is that justification must come along with metajustification, given that it is not possible to be justified in believing in the absence of metajustification. 
We could think that Klein's non-acceptance of the second clause of the PIJ has to do only with its content, and not with the idea of a metaepistemic requirement in itself. I bet this is probably true. However, the rejection of the metaepistemic requirement is not only explained by the rejection of the second clause of the PIJ, but, maybe principally, by the very idea that it is not necessary to have justification that the reason $\mathrm{r}$ is objectively available to $\mathrm{S}$ in order for $\mathrm{S}$ to have justification to believe $\mathrm{p}$ on the basis of $\mathrm{r}$. be that as it may, the point is not only that we may require a metaepistemic constraint, but that we must do so if we want to avoid the Bootstrapping Problem and if we want to use the sort of criticism Klein uses against Foundationalism.

In conclusion, an Infinitist should accept the following: if $S$ has justification to believe $\mathrm{p}$, then $\mathrm{S}$ has metajustification to believe $\mathrm{p}$, which means that if $\mathrm{S}$ has justification to believe $\mathrm{p}$, then $\mathrm{S}$ has an infinite number of available reasons to believe $\mathrm{p}$, and this "infinite number of available reasons" must include reasons with different functions, in particular, the reasons according to which S's reasons are effective - in other words, reasons according to which the reasons used by $\mathrm{S}$ are objectively available.

This conclusion appears to be in accordance with something like the second clause of the PIJ - which will avoid the Bootstrapping Problem - as well as in accordance with the criticism presented by Klein against Foundationalism.

In any case, I will not push this point further right now, because a defense of the inclusion of a specific metaepistemic requirement along with the other requirements of Infinitism will exceed the scope of this essay. The fundamental point is that Infinitism is capable of adopting the metaepistemic constraint, thus becoming a non-BKT view. This means that Infinitism is capable of avoiding the Bootstrapping Problem.

\section{Conclusion}

If Bootstrapping really is a problem, it is the result of having forgotten, or inverted, epistemic priority. The Bootstrapping Problem has been created by a theoretical intent that aims to provide solutions for a certain predicament, but fails to capture a fundamental aspect of the phenomenon of knowledge. Any resolution of the Bootstrapping Problem must reestablish the epistemic priority of second-order knowledge or justification. This can be achieved by imposing some constraints according to which we cannot know without properly knowing that we know.

This metajustification, or metaknowledge, requirement may leave us to face one skeptical threat, the infinite regress of metajustification. I think in this case we only have two options: to think that Skepticism is the right position, since we cannot attain appropriate justification for believing or else to think that we can deal with higher-order regresses in pretty much the same way Infinitism handles first-order regress. As long as we understand what exactly has to be 
infinite in Infinitism, we will see a way to deal with both kinds of regresses. Infinitism seems to be the view that can best accommodate the metaepistemic requirement that is necessary to avoid the Bootstrapping Problem. However, that is not my conclusion for now. My conclusion here is that the only way to avoid the Bootstrapping Problem is adopting a metaepistemic requirement according to which we cannot separate epistemic levels. ${ }^{32}$

32 This paper couldn't have been written without the help of Laura Catelli. I am also indebted to Claudio Almeida, for his many suggestions, and to Julio Burdzinski, for his help with the first version of this paper. 